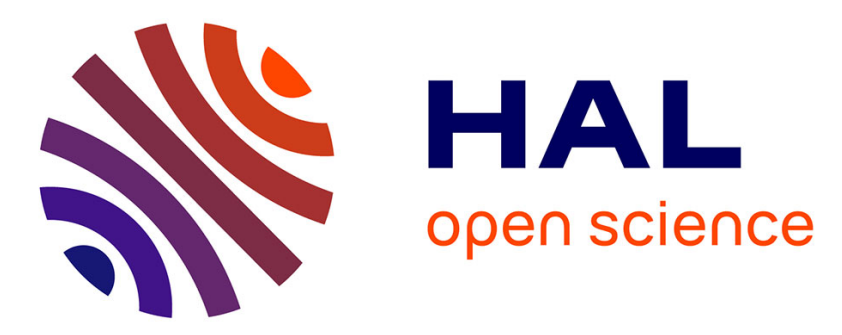

\title{
Configural olfactory learning in honeybees: Negative and positive patterning discrimination
}

Nina Deisig, Harald Lachnit, Martin Giurfa, Frank Hellstern

\section{To cite this version:}

Nina Deisig, Harald Lachnit, Martin Giurfa, Frank Hellstern. Configural olfactory learning in honeybees: Negative and positive patterning discrimination. Learning and Memory, 2001, 8 (2), pp.70-78. 10.1101/lm.8.2.70 . hal-02683213

\section{HAL Id: hal-02683213 https://hal.inrae.fr/hal-02683213}

Submitted on 1 Jun 2020

HAL is a multi-disciplinary open access archive for the deposit and dissemination of scientific research documents, whether they are published or not. The documents may come from teaching and research institutions in France or abroad, or from public or private research centers.
L'archive ouverte pluridisciplinaire HAL, est destinée au dépôt et à la diffusion de documents scientifiques de niveau recherche, publiés ou non, émanant des établissements d'enseignement et de recherche français ou étrangers, des laboratoires publics ou privés. 


\title{
Configural Olfactory Learning in Honeybees: Negative and Positive Patterning Discrimination
}

\author{
Nina Deisig, ${ }^{1}$ Harald Lachnit, ${ }^{2,3}$ Martin Giurfa, ${ }^{1}$ and Frank Hellstern ${ }^{1}$ \\ ${ }^{1}$ Neurobiology, Institute of Biology, Free University of Berlin, D-14195 Berlin, Germany; ${ }^{2}$ Department of Psychology, Philipps-University of \\ Marburg, D-35032 Marburg, Germany
}

\begin{abstract}
In an appetitive context, honeybees (Apis mellifera) learn to associate odors with a reward of sucrose solution. If an odor is presented immediately before the sucrose, an elemental association is formed that enables the odor to release the proboscis extension response (PER). Olfactory conditioning of PER was used to study whether, beyond elemental associations, honeybees are able to process configural associations. Bees were trained in a positive and anegative patterning discrimination problem. In the first problem, single odorants were nonreinforced whereas the compound was reinforced. In the second problem, single odorants were reinforced whereas the compound was nonreinforced. We studied whether bees can solve these problems and whether the ratio between the number of presentations of the reinforced stimuli and the number of presentations of the nonreinforced stimuli affects discrimination. Honeybees differentiated reinforced and nonreinforced stimuli in positive and negative patterning discriminations. They thus can process configural associations. The variation of the ratio of reinforced to nonreinforced stimuli modulated the amount of differentiation. The assignment of singular codes to complex odor blends could be implemented at the neural level: When bees are stimulated with odor mixtures, the activation patterns evoked at the primary olfactory neuropile, the antennal lobe, may be combinations of the single odorant responses that are not necessarily fully additive.
\end{abstract}

Animals can learn that an originally neutral stimulus can act as a predictor (conditioned stimulus; CS) for a biologically significant stimulus (unconditioned stimulus; US). Such a basic association between single stimuli can be acquired by a great variety of animals through classical conditioning (Pavlov 1927). In the natural world, however, stimuli rarely appear in isolation. Instead, they usually form complex stimuli (compounds) that enter into association with a US. A variety of models have been proposed to account for the processing of such compounds. Two main lines of reasoning can be distinguished. First, an elemental approach assumes that the compound $\mathrm{AB}$ will be represented as two elements, A and B, each of which becomes connected to the representation $\mathrm{X}$ of the US. The ability of either A alone or $\mathrm{B}$ alone to activate $\mathrm{X}$ will be determined by the strength of the A-X connection or B-X connection. The ability of the compound $\mathrm{AB}$ to activate $\mathrm{X}$ will be a function of the sum of strengths of the A-X and $\mathrm{B}-\mathrm{X}$ connections. The latter assumption thus assumes that "the whole equals the sum of its parts" (e.g., see Rescorla and Wagner 1972). Second, configural approaches assume that the representation of the compound $\mathrm{AB}$ is different from the simple sum of the individual representations of the elements $A$ and $B$ (i.e., "the

${ }^{3}$ Corresponding author.

E-MAIL Lachnit@mailer.uni-marburg.de; FAX 49-6421-2826621. Article and publication are at www.learnmem.org/cgi/doi/10.1101 $\operatorname{lm} .38301$. whole is different from the sum of its parts"). One influential configural approach retains the elemental summation principle but, in addition, assumes that the compound contains a supplementary (unobserved) stimulus. The bestknown version of this approach, the unique cue hypothesis, was originally proposed by Rescorla $(1972,1973)$ and by Whitlow and Wagner (1972). It assumes that a compound consists of its elements plus an additional stimulus that is unique to the compound. Other approaches assume that only configural information about the entire compound is used: The elements of a compound collectively enter into one single association (Pearce 1987, 1994).

Although elemental and/or configural associations drive the behavior of an animal, there are discrimination problems that can be used to distinguish between these approaches. Two of these discrimination problems are positive patterning and negative patterning. In positive patterning, two single stimuli are nonreinforced (A-, B-) whereas the compound of the same stimuli is reinforced $(\mathrm{AB}+)$. In negative patterning, the situation is reversed: Elemental stimuli are reinforced $(\mathrm{A}+, \mathrm{B}+)$ whereas the compound is nonreinforced $(\mathrm{AB}-)$. In principle, a positive patterning discrimination (i.e., the animal responds to the compound and not to the single elements) could also be solved through elemental learning because the associative strength of the elements could be subthreshold for the response. However, once added on compound presentation, they might result in

LEARNING \& MEMORY 8:70-78 @ 2001 by Cold Spring Harbor Laboratory Press ISSN1072-0502/01 \$5.00

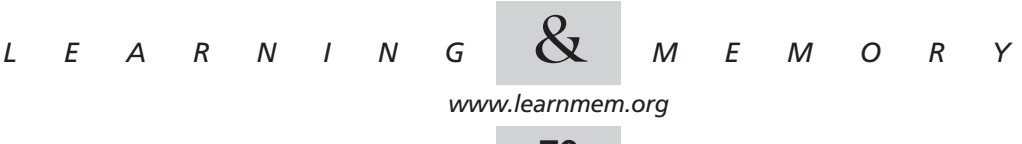


a suprathreshold associative strength. Such a summation would yield higher associative strength and, therefore, higher responsiveness to the compound. On the other hand, a negative patterning discrimination (i.e., the animal responds to the single elements and not to the compound) can only be solved if the animal is able to process configural representations, otherwise the sum of the excitatory strengths of the elements on compound presentation would always be greater than the strength of the single elements.

The honeybee, Apis mellifera L., offers an excellent opportunity to study the mechanisms of configural learning. In a natural context, honeybees learn a great variety of sensory cues usually presented as compounds and primarily associated with their nest and/or food sources, flowers (Menzel 1985; Menzel et al. 1993; Menzel and Müller 1996; Menzel and Giurfa 2000). Olfactory learning in the honeybee has been extensively characterized (see Hammer and Menzel 1995; Menzel and Müller 1996; Hammer 1997) and offers an appropriate preparation for studying configural learning in a controlled way. Harnessed honeybees can be conditioned to olfactory stimuli, either presented alone or as a compound (Bitterman et al. 1983). When the antennae of a hungry bee are touched with sucrose solution, the animal reflexively extends its proboscis to reach out to and suck the sucrose. Odors to the antennae do not release such a reflex in naive animals. If, however, an odor is presented immediately before sucrose solution (forward pairing), an association is formed that enables the odor to release the proboscis extension response (PER) in a following test. This effect is clearly associative and involves classical conditioning. Thus, the odor can be viewed as CS, and sucrose solution as the reinforcing US.

The first attempt to study configural learning in honeybees using olfactory conditioning of the PER was performed by Hellstern et al. (1995, 2000) and (in prep.). They performed a biconditional discrimination experiment and showed that when four different odors (A, B, C, D) are presented in binary combinations such that each element per se is equally presented with and without US (i.e., $\mathrm{AB}+$, $\mathrm{CD}+, \mathrm{AC}-, \mathrm{BD}-)$, bees learn to respond to the rewarded compounds and to inhibit respondes to the nonrewarded ones. Chandra and Smith (1998) obtained similar results using different odors in the same kind of experiment.

Chandra and Smith (1998) also reported a negative patterning experiment with odors as CSs and PER as response. Although bees solved the discrimination, the authors' experimental design does not allow concluding that a configural strategy was used to this end. When the bees were presented with either A or B alone, they were rewarded with sucrose solution (Sucr). When the compound $\mathrm{AB}$ was presented, the animals were confronted with an aversive stimulus (salt water; salt). With respect to the sucrose solution, therefore, the experiment of Chandra and Smith (1998) was indeed a negative patterning problem ( $A_{\text {Sucr }}$,
$\left.B_{\text {Sucr }}, A_{\text {noSucr }}\right)$. At the same time, however, it was a positive patterning problem with respect to salt water $\left(A_{\text {nosalt }}\right.$, $B_{\text {nosalt }}, A_{\text {Salt }}$ ). Hence, their design confounded positive and negative patterning. As mentioned above, a positive patterning discrimination can also be solved in an elemental way.

A first attempt to study configural learning in free-flying honeybees was made by Couvillon and Bitterman (1988). They trained bees to solve a negative and a positive patterning discrimination using stimuli of two different modalities, a green ring (color) and a peppermint scent (odor). Such stimuli are actually perceived in a sequence by the bees because both modalities have different detection ranges: Colors are detected at farther distances (Lehrer and Bischof 1995; Giurfa et al. 1996), whereas odors are detected closer to the target (von Frisch 1967). Sequential compounds might engage additional processes, such as second-order conditioning, that are not engaged in simultaneous compounds. However, sequential presentation of stimuli might also result in simultaneous compound processing as the first presented stimulus may produce some after-effect, which is simultaneous with the second processed stimulus.

Our experiments were primarily designed to study in a nonconfounded manner whether honeybees can solve positive as well as negative patterning discriminations and are, therefore, able to process configural associations. Moreover, as the difficulty of negative patterning seems to change with the ratio between the number of presentations of the reinforced elements and the number of presentations of the nonreinforced compound (Kehoe and Graham 1988), we studied the effect of varying such a ratio for negative patterning as well as for positive patterning.

\section{RESULTS}

\section{Positive Patterning}

We first investigated whether bees can solve a positive patterning discrimination $(\mathrm{A}-, \mathrm{B}-, \mathrm{AB}+)$. The ratios between the number of presentations of the reinforced compound $(\mathrm{CS}+\mathrm{AB}+)$ and those of the nonreinforced elements (CS-: A-, B-) were 1/1 (Group PP1/1; N = 70), 1/2 (Group PP1/2; $\mathrm{N}=70$ ), and $1 / 5$ (Group PP1/5; $N=70$ ). Figure 1a shows the percentage of proboscis extension response (\% PER) averaged across all trials of $\mathrm{A}-, \mathrm{B}-$, and $\mathrm{AB}+$, respectively, for each group. A Group $\times$ Element $(3 \times 2)$ analysis of variance (ANOVA) yielded no significant differences for the elements A and B (main effect element and Group $\times$ Element interaction: both $\mathrm{F}<1$ ); therefore, the elements were pooled for the next analyses.

Figure $1 \mathrm{~b}$ shows the course of conditioned responses (\% PER) to the compound $\mathrm{AB}+(\mathrm{CS}+)$ and the average responding to the elements $\mathrm{A}-$ and $\mathrm{B}-$ (CSs-) across blocks of trials for each of the three groups. In Group PP1/1 (upper panel) and in Group PP1/2 (middle panel), bees could correctly discriminate the CSs- from the CS+ early in the ac-

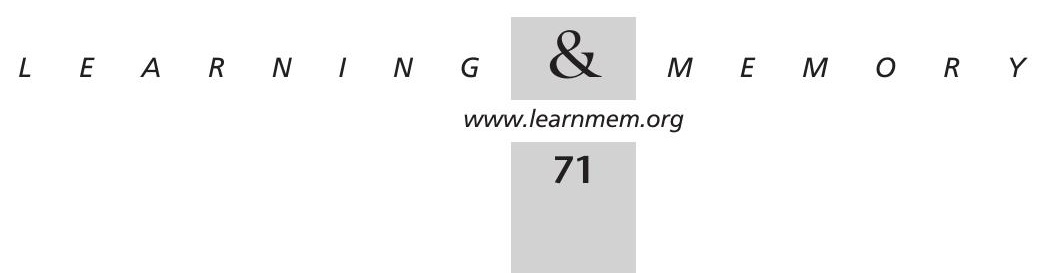


quisition. These two groups differed only slightly in their discrimination at the end of training. In Group PP1/5 (lower panel), responding to the $\mathrm{CS}+$ (reinforced compound $\mathrm{AB}+$ ) was not higher than that to the CSs- (nonreinforced elements A-, B-).

A Group $x$ Contingency $(3 \times 2)$ ANOVA was computed to compare the overall amount of differentiation across
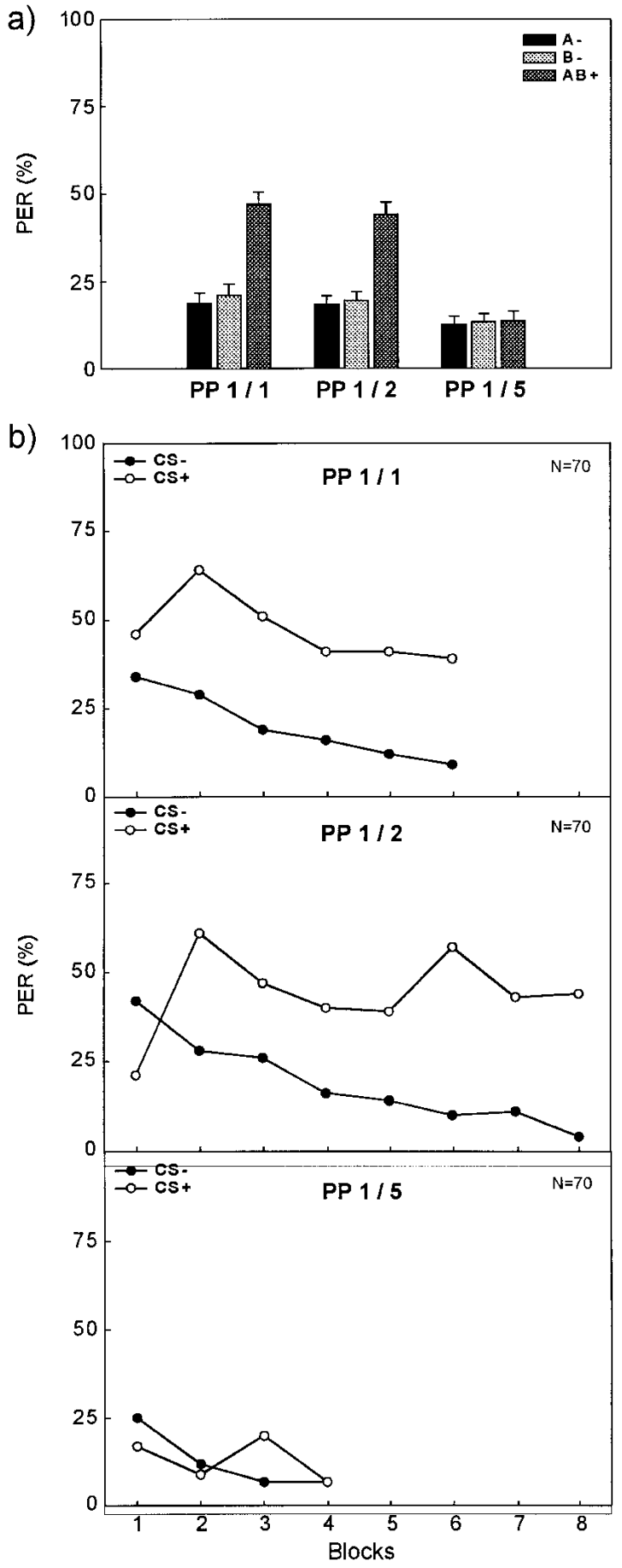

groups. We evaluated total acquisition by computing the average level of responding to the CS+ and to the pooled CSs - . The main effect group $\left(\mathrm{F}_{2207}=21.12, P<0.001\right)$, the main effect contingency $\left(\mathrm{F}_{1207}=140.52, P<0.001\right)$, and the interaction Group $\mathrm{x}$ Contingency $\left(\mathrm{F}_{2207}=32.82\right.$, $P<0.001)$ were significant. Because we found a significant interaction, we computed simple effects for contingency and group. Group PP1/1 $\left(\mathrm{F}_{1207}=110.78, P<0.001\right)$ and Group PP1/2 $\left(\mathrm{F}_{1207}=95.32, P<0001\right)$ showed significantly larger responses to CS+ than to CSs-, whereas Group PP1/5 $(\mathrm{F}<1)$ did not differentiate. The three groups did not differ in responding to the elements $\left(\mathrm{F}_{2207}=1.88, P>015\right)$, but they differed significantly in responding to the compound $\left(\mathrm{F}_{2207}=45.51, \quad P<0.001\right)$. A post hoc Tukey test $(\mathrm{HSD}=11.54)$ showed that responding to $\mathrm{AB}+$ in Group PP1/1 $(M=47.02)$ and in Group PP1/2 $(M=44.11)$ was similar but significantly larger in both groups than in Group PP1/5 ( $=13.56)$.

Although we found no significant differences in responding to $\mathrm{A}-$ and $\mathrm{B}-$ in our first analysis, one could argue that pooling across $\mathrm{A}-$ and $\mathrm{B}-$ might not be appropriate. If the bees idiosyncratically responded to one CS and not to the other, averaging their levels together could inadvertently produce the appearance of patterning. One way of analyzing the data would be to use responding to whichever CS in each subject yielded the level of responding closest to that of the compound. Analyzing the data in such a way, however, did not change the pattern of results we just reported.

In the following Group $\times$ Contingency $(3 \times 2)$ ANOVA, we compared the amount of differentiation at the end (last block) of acquisition. We again pooled responding to Aand $\mathrm{B}-$ in this analysis, because a Group $\mathrm{x}$ Element $(3 \times 2)$ ANOVA yielded no significant differences for the elements $A(M=8.17)$ and $B(M=5.78)$ in the last block (main effect element and Group x Element interaction: both $\mathrm{F}<1.08$ ). The Group $x$ Contingency ANOVA of the last block data yielded results very similar to the ANOVA of the overall response differentiation reported earlier. The main effect

Figure 1 Conditioned proboscis extension response (\% PER) across trials of a positive patterning discrimination. (a) Averaged \% PER across all trials of $\mathrm{A}-, \mathrm{B}-$, and $\mathrm{AB}+$ for Group PP1/1 (left), Group PP1/2 (middle), and Group PP1/5 (right). (b) Course of \% PER to the nonreinforced elements (CSs-; filled circles) and to the reinforced compound (CS+; open circles). The upper panel shows responding for Group PP1/1, with a ratio of $1 / 1$ between the number of presentations of the reinforced compound and the nonreinforced elements. Data were blocked to obtain six blocks of two CS- trials and six blocks of two CS+ trials. The middle panel shows responding for Group PP1/2 with a ratio of $1 / 2$ of reinforced and nonreinforced trials. Data were blocked to obtain eight blocks of two CS- trials and eight blocks of one CS+ trial. The lower panel shows responding for Group PP1/5, with a ratio of $1 / 5$ between the number of presentations of the reinforced compound and the nonreinforced elements. Data were blocked to obtain four blocks of five CS- trials and four blocks of one CS+ trial.

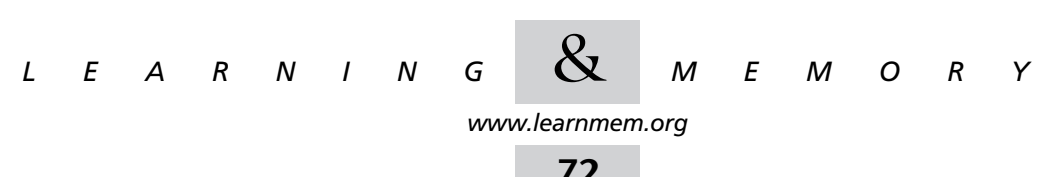


group $\left(\mathrm{F}_{2207}=8.75, P<0.001\right)$, the main effect contingency $\left(\mathrm{F}_{1207}=61.99, P<0.001\right)$, and the interaction Group $x$ Contingency $\left(\mathrm{F}_{2207}=17.87, P<0.001\right)$ were significant. Therefore, we again computed simple effects for contingency and group. Group PP1/1 $\left(\mathrm{F}_{1207}=33.01, P<0.001\right)$ and Group PP1/2 $\left(\mathrm{F}_{1207}=64.07, P<0.001\right)$ showed significantly larger responses to CS+ than to CSs-, whereas Group $\mathrm{PP} 1 / 5(\mathrm{~F}<1)$ showed no response differentiation at all. The three groups did not differ in responding to the elements $(\mathrm{F}<1)$, but they differed significantly in responding to the compound $\left(\mathrm{F}_{2207}=24.27, P<0.001\right)$. A post hoc Tukey test $(\mathrm{HSD}=16.72)$ showed that responding to $\mathrm{AB}+$ in Group PP1/1 ( $=37.14)$ and in Group PP1/2 $(\mathrm{M}=44.29)$ did not differ but was significantly larger in both groups than in Group PP1/5 $(M=7.31)$. When we analyzed these data using responding to whichever CS in each subject yielded the level of responding closest to that of the compound, once more the pattern of results did not change substantially.

These results indicate that bees can solve a positive patterning discrimination in appetitive odor conditioning of the PER. The variation of the ratio between the number of presentations of the reinforced compound $(\mathrm{CS}+\mathrm{AB}+)$ and those of the nonreinforced elements (CSs-: A-, B-) affected the total differentiation as well as the differentiation at the end of acquisition. A ratio of $1 / 5$ (with only four reinforced trials in a total of 24 trials) impaired the discrimination, whereas ratios of $1 / 2$ and $1 / 1$ yielded discriminations that were pronounced and comparable. The course of CS+ and CSs- responding in Groups PP1/1 and PP1/2 (especially from Block 1 to Block 2) directly contradicted the idea of subthreshold summation. Responding to $\mathrm{AB}+$ in both groups significantly increased from Block 1 to Block 2 $(\mathrm{t}[278]=5.72, P<0.001)$, whereas at the same time responding to A- and $\mathrm{B}-$ decreased from Block 1 to Block 2 $(\mathrm{t}[278]=2.28, P<0.03)$. Therefore, summation of the associative strengths of the single elements cannot explain the enhanced responsiveness to the compound. Although this finding supports configural processing of olfactory compounds by honeybees, only a discrimination task that does not admit elementary, additive solutions can show configural processing without doubt.

\section{Negative Patterning}

We, therefore, investigated whether bees can solve a negative patterning discrimination problem $(\mathrm{A}+, \mathrm{B}+, \mathrm{AB}-)$. Such a problem does not admit an elemental solution but can only be solved in a configural fashion. The ratios between the number of presentations of reinforced elements (CSs+: $\mathrm{A}+, \mathrm{B}+$ ) and those of the nonreinforced compound (CS-: AB-) were 1/1 (Group NP1/1; N = 70), 1/2 (Group NP1/2; $N=70$ ), and $1 / 3$ (Group NP1/3; $N=70$ ). Figure 2a shows $\%$ PER averaged across all trials of $\mathrm{A}+, \mathrm{B}+$, and $\mathrm{AB}-$, respectively, for each group. A Group $\times$ Element $(3 \times 2)$ ANOVA yielded no differences for the elements A $(M=39.01)$ versus $B(M=39.33)$. The main effect element and the Group $\mathrm{x}$ Element interaction were not significant (both $\mathrm{F}<1$ ). We, therefore, pooled the elements for the next analyses.

Figure $2 \mathrm{~b}$ shows the course of conditioned responses to the compound $\mathrm{AB}-(\mathrm{CS}-)$ and the average responding to the elements $\mathrm{A}+$ and $\mathrm{B}+(\mathrm{CSs}+)$ across blocks of trials for each group. Bees in all three groups (upper panel: Group NP1/1; middle panel: Group NP1/2; lower panel: Group $\mathrm{NP1/3}$ ) could discriminate correctly the CS- from the CSs+.

A Group $\times$ Contingency $(3 \times 2)$ ANOVA compared the overall amount of differentiation across groups. We evaluated total acquisition by computing the average level of responding to the pooled $\mathrm{CS}+$ and to the $\mathrm{CS}-$. The main effect group $\left(\mathrm{F}_{2207}=4.39, P<0.02\right)$, the main effect contingency $\left(\mathrm{F}_{1207}=313.30, P<0.001\right)$, and the interaction Group x Contingency $\left(\mathrm{F}_{2207}=6.06, P<0.003\right)$ were significant. Because we found a significant interaction, we computed simple effects for contingency and group. Group NP1/1 $\quad\left(\mathrm{F}_{1207}=109.75, \quad P<0.001\right), \quad$ Group $\quad \mathrm{NP} 1 / 2$ $\left(\mathrm{F}_{1207}=157.29, \quad P<0.001\right), \quad$ and $\quad$ Group $\quad \mathrm{NP} 1 / 3$ $\left(\mathrm{F}_{1207}=58.37, P<0.001\right)$ all showed significantly larger responses to CSs+ than to CS-. The three groups did not differ in responding to the nonreinforced compound $(\mathrm{F}<1)$, but they significantly differed in responding to the reinforced elements $\left(\mathrm{F}_{2207}=9.01, P<0.001\right)$. A post hoc Tukey test $(\mathrm{HSD}=10.24)$ showed that responding to CSs+ in Group NP1/1 $(\mathrm{M}=41.55)$ and in Group NP1/2 $(\mathrm{M}=45.00)$ was similar but significantly larger in both groups than in Group NP1/3 $(M=30.96)$. When we analyzed these data using responding to whichever CS in each subject yielded the level of responding closest to that of the compound, the pattern of results did not change substantially with one exception: The simple effect for Group NP1/3 no longer was significant.

In the following Group $\times$ Contingency $(3 \times 2)$ ANOVA, we compared the amount of differentiation in the last block of acquisition. We again pooled responding to $\mathrm{A}+$ $(M=34.76)$ and $B+(M=40.95)$ in this analysis, because a Group $\times$ Element $(3 \times 2)$ ANOVA yielded no significant differences for the elements A and B (main effect element and Group $\mathrm{x}$ Element interaction: both $\mathrm{F}<2.22$, smallest $P>0.14)$ in the last block. The Group $x$ Contingency ANOVA of the last block data yielded the following results. The main effect group $\left(\mathrm{F}_{2207}=1.24, P>0.29\right)$ was not significant. The main effect contingency $\left(\mathrm{F}_{1207}=205.70\right.$, $P<0.001)$ and the interaction Group $\times$ Contingency $\left(\mathrm{F}_{2207}=3.12, P<0.05\right)$ were significant. We, therefore, computed simple effects for contingency and group. Group NP1/1 $\left(\mathrm{F}_{1207}=43.18, P<0.001\right)$, Group NP1/2 $\left(\mathrm{F}_{1207}=101.95, P<0.001\right)$, and Group NP1/3 $\left(\mathrm{F}_{1207}=66.81\right.$, $P<0.001)$ all showed significantly larger responses to CSs+ than to CS-. The three groups did not differ in responding to the nonreinforced compound $(\mathrm{F}<1)$, but they differed

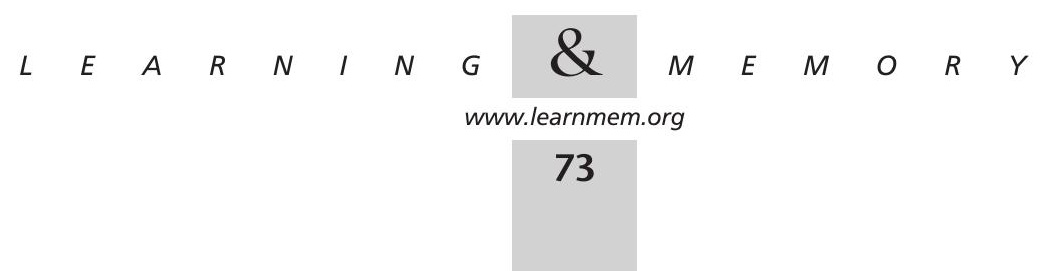


significantly in responding to the reinforced elements $\left(\mathrm{F}_{2207}=4.93, \quad P<0.009\right)$. A post hoc Tukey test $(\mathrm{HSD}=12.85)$ showed that responding to CSs+ in Group NP1/1 $(M=32.14)$ and in Group NP1/3 $(M=36.43)$ was similar but it was significantly smaller in both groups than in Group NP1/2 $(M=45.00)$. When we analyzed these data using responding to whichever $\mathrm{CS}$ in each subject yielded
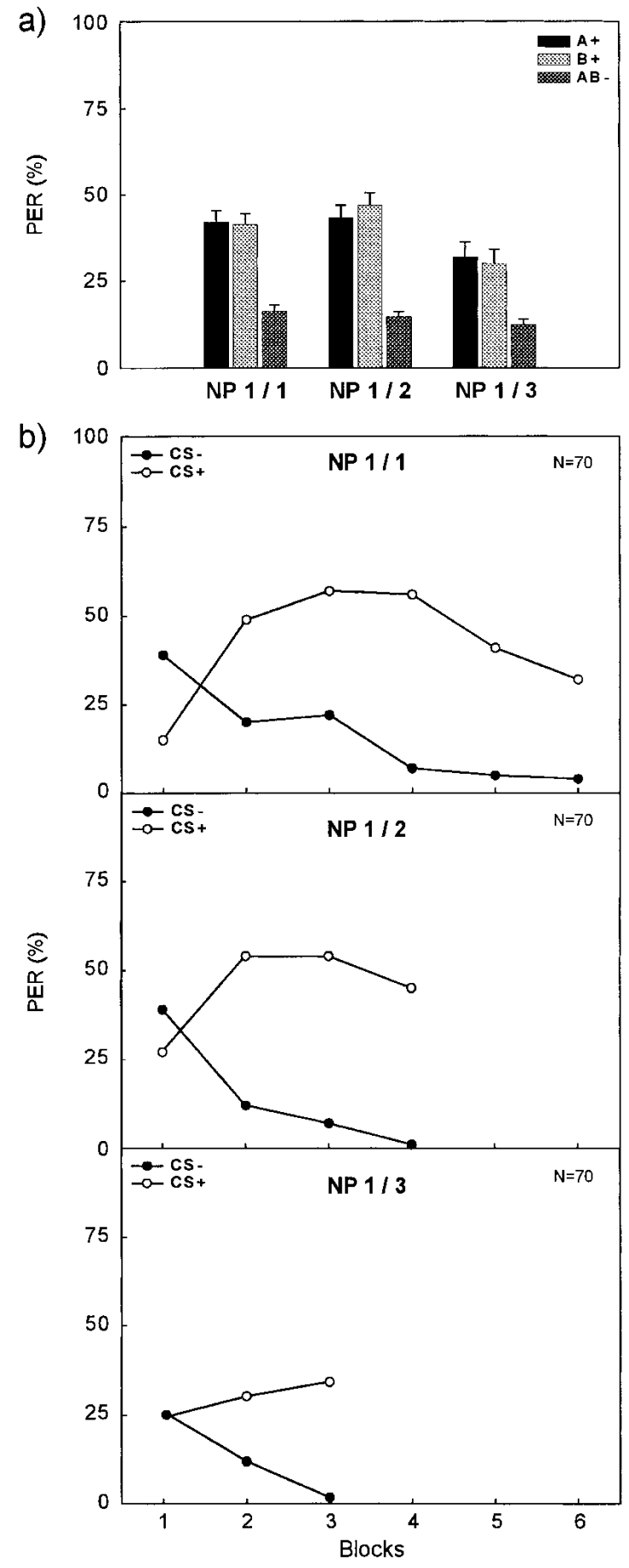

the level of responding closest to that of the compound, again the pattern of results did not change substantially.

These results clearly indicate that bees can solve a negative patterning discrimination in appetitive odor conditioning of the PER. The variation of the ratio between the reinforced elements (CSs+) and the nonreinforced compound (CS-) affected the overall differentiation as well as the differentiation reached at the end of acquisition. Decreasing the ratio from $1 / 1$ to $1 / 2$ increased the discrimination at the end of acquisition, although the overall discrimination did not differ significantly. Decreasing the ratio even more, to $1 / 3$ (with only three reinforced trials per element and 18 nonreinforced compound trials), weakened the overall discrimination compared with both other groups as well as the discrimination at the end of training compared with Group NP1/2. The increase in differentiation observed from the first to the second ratio $(1 / 1$ to $1 / 2)$ is in accordance with data obtained in aversive conditioning of the nictitating membrane response in rabbits (Kehoe and Graham 1988).

\section{DISCUSSION}

Our results provide clear evidence that honeybees can learn to differentiate single odors from compounds containing the same odors in appetitive conditioning procedures according to positive and negative patterning schedules. So far, positive and negative patterning discriminations have been shown to occur in humans (Hull 1940; Lachnit and Kimmel 1993, 2000; Lachnit and Kinder 2000; Lachnit et al. 2000), dogs (Woodbury 1943), rats (Rescorla 1972, 1973), and rabbits (Kehoe and Graham 1988). The two previous studies that attempted to study negative and positive patterning in bees (Couvillon and Bitterman 1988; Chandra and Smith 1998) pose some difficulties because of different methodological problems (see Introduction). In the current experiments, we conclusively showed that bees can solve configural discrimination problems. These findings are in line with those of Hellstern et al. (1995, 2000) and

Figure 2 Conditioned proboscis extension response (\% PER) across trials of a negative patterning discrimination. (a) Averaged \% PER across all trials of $\mathrm{A}+, \mathrm{B}+$, and $\mathrm{AB}-$ for Group NP1/1 (left), Group NP1/2 (middle), and Group NP1/3 (right). (b) Course of \% PER to the reinforced elements (CSs+; open circles) and to the nonreinforced compound (CS-; filled circles). The upper panel shows responding for Group NP1/1, with a ratio of 1/1 between the number of presentations of the reinforced elements and the nonreinforced compound. Data were blocked to obtain six blocks of two CS+ trials and six blocks of two CS- trials. The middle panel shows responding for Group NP1/2 with a ratio of $1 / 2$ of reinforced and nonreinforced trials. Data were blocked to obtain four blocks of two CS+ trials and four blocks of four CS- trials. The lower panel shows responding for Group NP1/3 with a ratio of $1 / 3$ of reinforced and nonreinforced trials. Data were blocked to obtain three blocks of two CS+ trials and three blocks of six CS- trials.

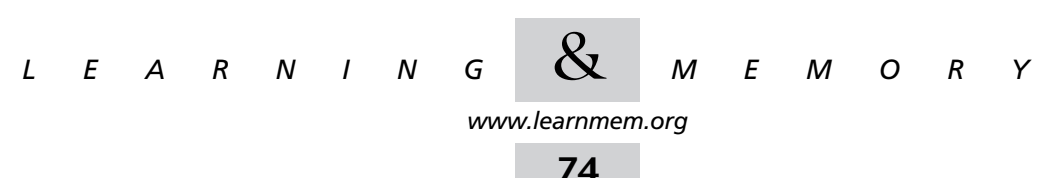


Chandra and Smith (1998), who showed that bees can solve a biconditional discrimination problem with four different odors.

In positive patterning, differential responding to the nonreinforced elements did not vary between groups. Overall responding as well as responding in the last block to the reinforced compound decreased, when the number of reinforcements was reduced from eight to four. Four reinforcements in 24 trials might not have been enough for differential conditioning. The results of the positive patterning discrimination support the conclusion that bees are able to process configural associations. As pointed out by Bellingham et al. (1985), the elemental account of positive patterning can explain responding at any given time of training but is unable to account for the development of responding observed in the course of training. The course of differentiation between the CS+ and the CSs- from Block 1 to Block 2 in the two groups PP1/1 and PP1/2 directly contradicted the idea of subthreshold summation. As in both groups responding to the reinforced compound increased and responding to nonreinforced elements decreased, summation of the associative strengths of the single elements cannot explain the enhanced responsiveness for the compound. Therefore, configural representations should be involved in the positive patterning discrimination.

The successful response differentiation found in negative patterning cannot be explained by the elemental summation principle. Such a principle predicts that the excitatory associations of the elements $(\mathrm{A}+, \mathrm{B}+)$ will lead to summation when the $\mathrm{AB}-$ compound is presented. The socalled unique cue hypothesis was introduced to overcome this and other problems of elemental theories (Whitlow and Wagner 1972). According to this hypothesis, the presentation of a compound stimulus not only activates the representations of the elements but also the representation of a hypothetical cue (U), which is unique to the combination of the elements (Rescorla 1973). This unique cue codes the common presentation of a certain configuration of stimuli. The response to an $\mathrm{AB}$ compound may thus be analyzed as the sum of three associative strengths-those of the elements $\mathrm{A}$ and $\mathrm{B}$ and of the unique cue $\mathrm{U}$. With regard to the negative patterning task, the discrimination that has to be learned becomes $\mathrm{A}+, \mathrm{B}+$ versus $\mathrm{AB}-$. This implies that in $\mathrm{AB}-$ trials the unique cue will acquire inhibitory associative strength that will counter the excitatory associative strengths of the elements $\mathrm{A}$ and $\mathrm{B}$. Thus, the unique cue assumption can principally explain mastering of a negative patterning task.

In most patterning experiments performed with nonhuman animals, the two elements of the compound belonged to different sensory modalities (i.e., tone and light; Hull 1940; Rescorla 1972, 1973; Bellingham et al. 1985), but there were also studies using stimuli of a single modality (e.g., Pearce and Redhead 1993). In our current experi- ments, all stimuli belonged to the olfactory modality. In such a case afferent neural interactions (as defined by Hull [1945]) might favor the emergence of configural instead of elemental representations plus a unique cue (for related discussions, see also Rescorla and Coldwell 1995; Lachnit and Kinder 2000; Brandon et al. 2000). Thus, the discrimination problems of our experiments might have been solved using a pure configural representation (see Pearce $1987,1994)$ instead of relying on an additional unique cue.

Decreasing the ratio of reinforced to nonreinforced trials in our negative patterning experiment resulted in group differences between responses to reinforced elements, whereas the nonreinforced compounds did not differ in overall differentiation or in differentiation at the end of training. With respect to overall differentiation, reducing the number of reinforcements from eight to six (three per element) resulted in a significant decrease in responding to the elements. Reducing the number of reinforcements from 12 to eight (from six to four per element) and increasing the number of nonreinforced presentations of the compound from 12 to 16, however, led to a significant increase in responding to the elements, although responding to the compound remained the same. This pattern of results can neither be explained by the unique cue hypothesis nor by Pearce's configural theory. Nevertheless, some kind of configural processing must have taken place to solve the discrimination problem.

Interestingly, the neurobiological basis of olfactory coding in the honeybee can yield some light on the problem of elemental versus configural compound processing. Although this issue has not yet been raised at the neural level, the basic principles of olfactory coding at the level of the bee antennal lobe, the primary olfactory neuropile in the insect brain, are now known (Joerges et al. 1997; Galizia and Menzel 2000). The antennal lobe is a spherical structure with 160 glomeruli innervated by about 60,000 chemoreceptor axons. Optical recordings in vivo of the antennal lobe using calcium-sensitive fluorescent dyes during olfactory stimulation showed that odors are coded as specific spatio-temporal excitation patterns (Joerges et al. 1997). Specific ensembles of glomeruli represent odors in a combinatorial manner. Suggestively, when the bees were stimulated with mixtures of odors, the activation patterns evoked at the antennal lobe were combinations of the single odorant responses that were not fully additive, thus indicating the formation of singular codes for olfactory compounds. Moreover, parallel olfactory elemental conditioning of the PER and imaging studies of the antennal lobe showed that the neural representation of a trained odor becomes more pronounced and distinct from a nonrewarded odor, but its general features do not change (Faber et al. 1999). This indicates that elemental learning intensifies the neural code for the learned signal but does not create a new representation. However, it still needs to be studied whether con-

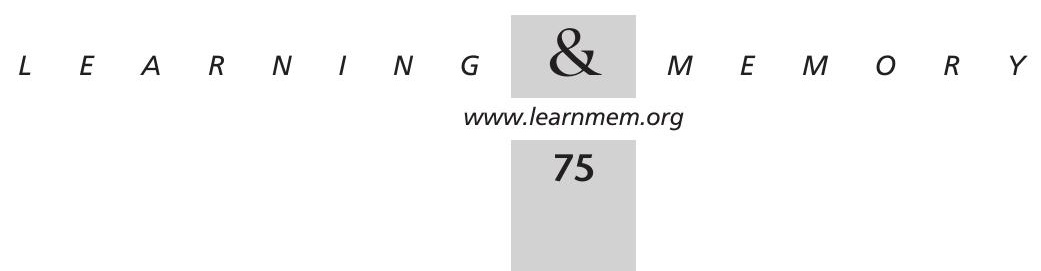


figural learning yields the same effect at the level of the neural olfactory representation.

Configural processing of olfactory compounds may have a particular biological relevance for honeybees. Bees live in a rich sensory world and, therefore, are confronted with a large number of stimuli. Such stimuli usually appear in compounds of the same or different modalities. Therefore, it is important for bees to be able to identify and distinguish compounds, which can function as predictors for important reinforcing events. In the olfactory modality, bees can generalize their choice behavior to novel blends that share some single odorants with the originally rewarded blend (Laloi et al. 2000). However, the assignment of singular codes or entities to complex odor blends could also be useful in a foraging context as generalization on the basis of single odorants may lead to errors, that is, to nonrewarding flower species. Odor compounds may vary according to nectar productivity in a flower, that is, a flower in a nonproductive stage may present a given odor blend that can be thus associated with absence of reward; in a productive stage, however, further odors may be added to the original blend, thus creating a new compound that partially overlaps with the former one. In that sense, configural processing of odor mixtures may allow identifying and discriminating a particular rewarding flower species from nonrewarding species having similar odors.

\section{MATERIALS AND METHODS}

Honeybees, (Apis mellifera L.), were caught at the entrance of outdoor hives at the beginning of each experimental day. Each bee was placed in a small glass vial and cooled in a freezer until it ceased movement. Individuals were mounted into restraining harnesses so they could only move their antennae and mouthparts, including the proboscis (Takeda 1961; Bitterman et al. 1983). Animals were then kept undisturbed in a room of the laboratory for approximately $2 \mathrm{~h}$. Ten minutes before starting the experiments, each subject was checked for intact PER by lightly touching one antenna with a toothpick imbibed with sucrose solution without subsequent feeding. Extension of the proboscis beyond a virtual line between the open mandibles was counted as PER (unconditioned response). Animals that did not show the reflex $(<5 \%)$ were not used in the experiments.

The US was always $1.25 \mathrm{M}$ sucrose solution. The CSs were the odorants linalool, limonene, 1-Hexanol and 2-Octanol (SIGMA). On each experimental day, $4 \mu \mathrm{L}$ of pure odorant were applied onto a fresh strip of filter paper. The paper strips were then placed into a 1-mL plastic syringe and mounted in an odor-supplying device (for details, see Gerber and Menzel 2000). When the bee was placed in front of the device, it received a gentle, constant flow of clean air provided by a standard aquarium pump. Computer-driven solenoid valves (Lee Company) controlled airflow delivery. During periods of odorant delivery, the airflow was shunted through a syringe containing the odorant. In that way, a single odorant or a compound of two odorants could be delivered to the bee. In the later case, the valves corresponding to two different syringes were opened simultaneously so the airflow arriving at the antennae of the bee contained the two odors as a compound. An exhaust sys- tem was mounted behind the bees to remove odor-loaded air. Between conditioning trials, bees were placed in front of a small van delivering a constant airflow to the animals. In that way, the mechanical airflow stimulation during training could not act as a predictor of the US.

At the beginning of each trial, the subject was placed in front of the odor-delivering device for $15 \mathrm{sec}$ to allow familiarization with the training situation. Thereafter, the CS was presented for $6 \mathrm{sec}$. In reinforced trials, US onset occurred 3 sec after CS onset. Both antennae were lightly touched with a toothpick imbibed with the sucrose solution, and after proboscis extension the bee was allowed to feed for $2 \mathrm{sec}$. Therefore, the inter-stimulus interval was $3 \mathrm{sec}$, and the overlap between CS and US was also $3 \mathrm{sec}$. Nonreinforced trials consisted of 6-sec CS presentation without reward. After each conditioning trial, animals were returned to their resting position. The intertrial interval was $8 \mathrm{~min}$.

During acquisition we recorded whether a bee extended its proboscis after onset of the odor (CS) and before presentation of the sucrose solution (US), so the anticipatory response recorded could not have been evoked directly by the US. The criteria for the occurrence of a conditioned response were the same as for the unconditioned one (extension of the proboscis beyond the virtual line between the open mandibles) except that it should occur in response to the olfactory stimulation. Multiple responses during a CS were counted as a single PER. After experiments were finished, all animals were again tested for PER. If an animal did not respond, it was discarded $(<10 \%)$. The same was the case for animals that never or always responded during conditioning.

In two experiments we investigated whether bees can solve a positive patterning discrimination $(\mathrm{A}-, \mathrm{B}-, \mathrm{AB}+)$ and a negative patterning discrimination $(\mathrm{A}+, \mathrm{B}+, \mathrm{AB}-)$. Experiments were run in an alternated way, that is, $1 \mathrm{~d}$ was assigned to positive patterning and the next day to negative patterning. An average of 20 bees per day was used. Bees were divided in three groups corresponding to three different ratios between elements and compound (i.e., approx. seven bees per group per day). As for each group, a total of 70 bees were trained; a complete experiment lasted about $10 \mathrm{~d}$.

\section{Positive Patterning}

In this experiment, presentation of the pure odorants was nonreinforced $(\mathrm{A}-, \mathrm{B}-)$ whereas presentation of the mixture was reinforced $(\mathrm{AB}+$ ). The four odorants (linalool, 1-hexanol, limonene, and 2-octanol) were used as A and B in two subgroups. One subgroup was trained with linalool and 1-hexanol and the other subgroup with limonene and 2-octanol. To reduce the complexity of the presentation of results, we only report analyses of the pooled data. Our conclusions also hold for the more detailed analyses. Three independent groups of bees were tested with three different ratios between the number of CSs+ presentations and the number of CSpresentations. The ratios were $1 / 1,1 / 2$, and $1 / 5$. Each group received a total of 24 training trials. Thus, bees in Group PP1/1 received six $\mathrm{A}-$ trials, six $\mathrm{B}-$ trials, and $12 \mathrm{AB}+$ trials. Bees in Group $\mathrm{PP} 1 / 2$ received eight $\mathrm{A}-$ trials, eight $\mathrm{B}-$ trials, and eight $\mathrm{AB}+$ trials. Bees in Group PP1/5 received $10 \mathrm{~A}-$ trials, $10 \mathrm{~B}-$ trials, and four $\mathrm{AB}+$ trials. Within each group, the sequence of $\mathrm{CS}+$ and CSs- trials was randomized and changed for each day.

\section{Negative Patterning}

In this experiment, presentation of the pure odorants was reinforced $(\mathrm{A}+, \mathrm{B}+)$, whereas presentation of the mixture was nonreinforced $(\mathrm{AB}-)$. As in the positive patterning experiment, the four

\section{$\begin{array}{lllllllllllllll}\text { www.learnmem.org } & & & & & & & & & & & & \end{array}$}


odorants (linalool, 1-hexanol, limonene, and 2-octanol) were used as $A$ and $B$ in two subgroups. One subgroup was trained with linalool and 1-hexanol and the other subgroup with limonene and 2-octanol. To reduce the complexity of the presentation of results, we only report analyses of the pooled data. Our conclusions also hold for the more detailed analyses. Three independent groups of bees were tested with three different ratios between the number of $\mathrm{CS}+$ presentations and the number of CS- presentations. The ratios were $1 / 1,1 / 2$, and $1 / 3$. Each group received a total of 24 training trials. Thus, for Group NP1/1, six A+trials, six B+trials, and $12 \mathrm{AB}-$ trials were presented. Group NP1/2 received four $\mathrm{A}+$ trials, four $\mathrm{B}+$ trials, and $16 \mathrm{AB}-$ trials, and Group NP1/3 was trained with three $\mathrm{A}+$ trials, three $\mathrm{B}+$ trials, and $18 \mathrm{AB}-$ trials. Within each group, the sequence of CSs+ and CS- trials was randomized and changed for each day.

\section{Data Transformation and Statistical Analyses}

In both experiments, we measured the percentage of conditioned responses (\% PER) in successive CS+ trials (omitting the randomly interspersed CS- trials) and in successive CS- trials (omitting the randomly interspersed $\mathrm{CS}+$ trials).

In the positive patterning experiment, bees in Group PP1/1 received six $\mathrm{A}-$, six $\mathrm{B}-$, and $12 \mathrm{AB}+$ trials. Data were grouped to obtain six blocks of two CS- trials and six blocks of two CS+ trials. Bees in Group PP1/2 received eight $\mathrm{A}_{-}$, eight $\mathrm{B}-$, and eight $\mathrm{AB}+$ presentations. Data were grouped to obtain eight blocks of two CS- trials and eight blocks of one CS+ trial. Bees in Group PP1/5 had $10 \mathrm{~A}-, 10 \mathrm{~B}-$ and four $\mathrm{AB}+$ trials. Thus, we grouped our data to obtain four blocks of five CS- trials and four blocks of one CS+ trial.

Similarly, in the negative patterning experiment, bees in Group NP1/1 received six A+, six B+, and $12 \mathrm{AB}-$ trials. Data were grouped to obtain six blocks of two CS+ trials and six blocks of two CS- trials. Bees in Group NP1/2 received four A+, four B+, and 16 $\mathrm{AB}-$ trials. Data were grouped to obtain four blocks of two CS+ trials and four blocks of four CS- trials. Bees in Group NP1/3 received three $\mathrm{A}+$, three $\mathrm{B}+$, and $18 \mathrm{AB}-$ presentations. Data were grouped to obtain three blocks of two CS+ trials and three blocks of six CS- trials.

For both positive and negative patterning experiments, ANOVAs were used for between-group as well as within-group comparisons. Although ANOVA is usually not allowed in case of dichotomous data such as those of the PER, Monte Carlo studies have shown that ANOVA can be used under certain conditions (Lunney 1970), which all are met by the two experiments reported here. Where necessary, Tukey tests were used to perform post hoc comparisons. The alpha level was set to 0.05 for all analyses.

\section{ACKNOWLEDGMENTS}

We thank Bernhard Komischke, Dagmar Malun, Jean-Christophe Sandoz, Marco Schubert, and Silke Stach for helpful discussions. We especially thank Randolf Menzel for criticisms on an earlier version of this work and for encouragement and valuable support. Comments of two anonymous reviewers helped to improve the manuscript.

This work was supported by grants DFG La 564/10-1, DFG Me 365/32-1, and DFG Gi 291/3-1 of the National German Science Foundation (Deutsche Forschungsgemeinschaft: DFG) and by the special program SFB 515 of the National German Science Foundation (grant $\mathrm{C} 7$ to M.G. and D.M.).

The publication costs of this article were defrayed in part by payment of page charges. This article must therefore be hereby marked "advertisement" in accordance with 18 USC section 1734 solely to indicate this fact.

\section{REFERENCES}

Bellingham, W.P., Gillette-Bellingham, K., and Kehoe, E.J. 1985. Summation and configuration in patterning schedules with the rat and rabbit. Anim. Learn. Behav. 13: 152-164.

Bitterman, M.E., Menzel, R., Fietz, A., and Schäfer, S. 1983. Classical conditioning of proboscis extension in honeybees (Apis mellifera). $J$. Comp. Psychol. 97: 107-119.

Brandon, S.E., Vogel, E.H., and Wagner, A.R. 2000. A componential view of configural cues in generalization and discrimination in Pavlovian conditioning. Behav. Brain Res. 110: 67-72.

Chandra, S. and Smith, B.H. 1998. An analysis of synthetic processing of odor mixtures in the honeybee (Apis mellifera). J. Exp. Biol. 201: 3113-3121.

Couvillon, P.A. and Bitterman, M.E. 1988. Compound-component and conditional discrimination of colors and odors by honeybees: Further tests of a continuity model. Anim. Learn. Behav. 16: 67-74.

Faber, T., Joerges, J., and Menzel, R. 1999. Associative learning modifies neural representations of odors in the insect brain. Nature Neurosci. 2: 74-78.

Galizia, C.G. and Menzel, R. 2000. Odour perception in honeybees: Coding information in glomerular patterns. Curr. Opin. Neurobiol. 10: $504-510$.

Gerber, B. and Menzel, R. 2000. Contextual modulation of memory consolidation. Learn. \& Mem. 7: 151-158.

Giurfa, M., Vorobyev, M. Kevan, P.G., and Menzel, R. 1996. Detection of coloured stimuli by honeybees: Minimum visual angles and receptor specific contrast. J. Comp. Physiol. (A) 178: 699-709.

Hammer, M. 1997. The neural basis of associative reward learning in honeybees. TINS 20: 245-252.

Hammer, M. and Menzel, R. 1995. Learning and memory in the honeybee. J. Neurosci. 15: 1617-1630.

Hellstern, F., Wüstenberg, D., and Hammer, M. 1995. Contextual learning in honeybees under laboratory conditions. In Learning and memory. Proceedings of the 25th Göttingen Neurobiology Conference (eds. $\mathrm{N}$ Elsner and R. Menzel), abstract 30. Stuttgart.

Hull, C.L. 1940. Exploration in the patterning of stimuli conditioned to the GSR. J. Exp. Psychol. 27: 95-110.

. 1945. The discrimination of stimulus configuration and the hypothesis of afferent neural interaction. Psychol. Rev. 5: 133-142.

Joerges, J., Küttner, A., Galizia, C.G., and Menzel, R. 1997. Representations of odors and odor mixtures visualized in the honeybee brain. Nature 387: 285-288.

Kehoe, E.J. and Graham, P. 1988. Summation and configuration: Stimulus compounding and negative patterning in the rabbit. J. Exp. Psychol. Anim. Behav. Process. 14: 320-330.

Lachnit, H. and Kimmel, H.D. 1993. Positive and negative patterning in human classical skin conductance response conditioning. Anim. Learn. Behav. 21: 314-326.

- 2000. Experimental manipulation of a unique cue in Pavlovian SCR conditioning with humans. Biol. Psychol. 50: 157-171.

Lachnit, H. and Kinder, A. 2000. Stimulus representations in human Pavlovian conditioning: Implications of missing negative transfer across response systems. Q. J. Exp. Psychol. B 53: 209-224.

Lachnit, H., Reinhard, G., and Kimmel, H.D. 2000. Further investigations of stimulus coding in nonlinear discrimination problems. Biol. Psychol. 55: $57-73$

Laloi, D., Bailez, O., Blight, M., Roger, B., Pham-Delègue, M.-H., and Wadhams, L. 2000. Recognition of complex odors by restrained and free-flying honeybees, Apis mellifera. J. Chem. Ecol. 26: 2307-2319.

Lehrer, M. and Bischof, S. 1995. Detection of model flowers by honeybees: The role of chromatic and achromatic contrast. Naturwissenschaften 82: 145-147.

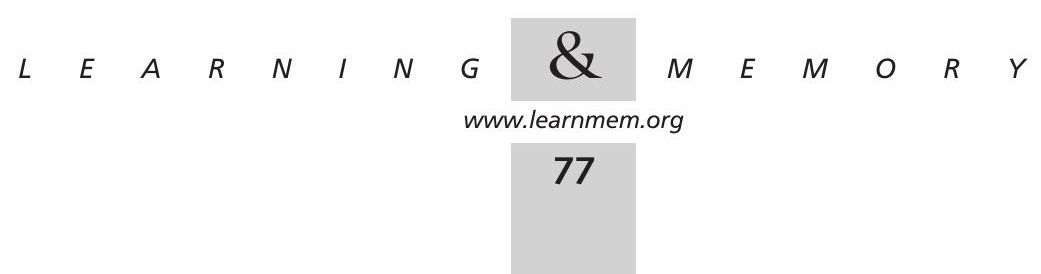


Lunney, G.H. 1970. Using analysis of variance with a dichotomous dependent variable: An empirical study. J. Educat. Meas. 7: 263-269.

Menzel, R. 1985. Learning in honey bees in an ecological and behavioral context. In Experimental behavioral ecology (eds. B. Hölldobler and M. Lindauer), pp. 55-74, Fischer, Stuttgart, Germany.

Menzel, R., Greggers, U., and Hammer, M. 1993. Functional organization of appetitive learning and memory in a generalist pollinator, the honey bee. In Insect learning: Ecological and evolutionary perspectives (eds. D. Papaj and A.C. Lewis), pp. 79-125. Chapman and Hall, New York.

Menzel, R. and Giurfa, M. 2000. Cognitive architecture of a minibrain: The honeybee. TICS (in press).

Menzel, R. and Müller, U. 1996. Learning and memory in honeybees: From behavior to neural substrates. Annu. Rev. Neurosci. 19: 379-404.

Mobbs, P.G. 1982. The brain of the honeybee Apis mellifera I. The connections and spatial organization of the mushroom bodies. Phil. Trans. R. Soc. Lond. B 298: 309-354.

Pavlov, I.P. 1927. Lectures on conditioned reflexes. International Publishers, New York.

Pearce, J.M. 1987. A model of stimulus generalization in Pavlovian conditioning. Psychol. Rev. 94 : 61-73.

- 1994. Similarity and discrimination: A selective review and a connectionist model. Psychol. Rev. 101: 587-607.

Pearce, J.M. and Redhead E.S. 1993. The influence of an irrelevant stimulus on two discriminations. J. Exp. Psychol. Anim. Behav. Process. 19: 180-190.

Rescorla, R.A. 1972. Configural conditioning in discrete-trial bar pressing. J. Comp. Physiol. Psychol. 79: 307-317.
- 1973. Evidence for unique stimulus account of configural conditioning. J. Comp. Physiol. Psychol. 85: 331-338.

Rescorla, R.A. and Coldwell, S.E. 1995. Summation in autoshaping. Anim. Learn. Behav. 23: 314-326.

Rescorla, R.A. and Wagner, A.R. 1972. A theory of Pavlovian conditioning: Variations in the effectiveness of reinforcement and nonreinforcement. In: Classical conditioning 2: Current research and theory (eds. A. H. Black and W. F. Prokasy), pp. 64-99. Appleton-Century-Crofts, New York.

Rudy, J.W. and Sutherland, R.J. 1995. Configural association theory and the hippocampal formation: An appraisal and reconfiguration. Hippocampus 5: 375-389.

Takeda, K. 1961. Classical conditioned response in the honey bee. $J$. Insect Physiol. 6: 168-179.

von Frisch, K. 1967. The dance language and orientation of bees. Harvard University Press, Cambridge.

Whitlow, J.W. and Wagner, A.R. 1972. Negative patterning in classical conditioning: Summation of response tendencies to isolable and configural components. Psychonom. Sci. 27: 299-301.

Woodbury, C.B. 1943. The learning of stimulus patterns by dogs. J. Comp. Psychol. 35: 29-40.

Received December 11, 2000; accepted in revised form February 2, 2001.

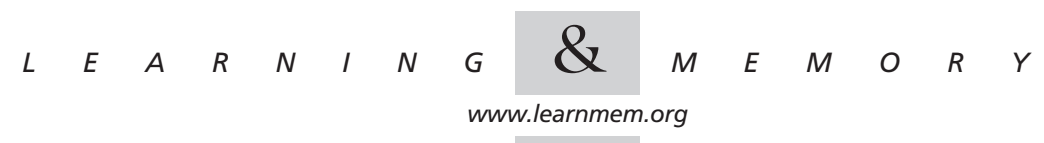




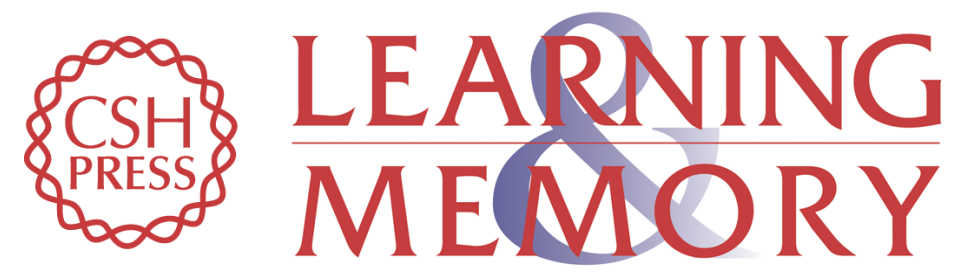

\section{Configural Olfactory Learning in Honeybees: Negative and Positive Patterning Discrimination}

Nina Deisig, Harald Lachnit, Martin Giurfa, et al.

Learn. Mem. 2001 8: 70-78

Access the most recent version at doi:10.1101//m.38301

References This article cites 31 articles, 3 of which can be accessed free at: http://learnmem.cshlp.org/content/8/2/70.full.html\#ref-list-1

Email Alerting Receive free email alerts when new articles cite this article - sign up in the box at the Service top right corner of the article or click here.

To subscribe to Learning \& Memory go to:

http://learnmem.cshlp.org/subscriptions 